\title{
Post Myocardial Infarction VSD Device Closure
}

\section{Abstract}

Post acute myocardial infarction ventricular septal defect (VSD) or rupture is a rare lethal complication and curry very high surgical mortality and morbidity [1-10], but interventional closure of this defects by cardiac catheterization is an excellent alternative method with much better results especially in good centers (3.4.5). Our case is the first case in UAE with large post MI VSD which managed successfully and survived after device closure.

Case Report
Volume 4 Issue 3 - 2015
Mahmoudl AlSoufi ${ }^{1 *}$ and AyaHabbal ${ }^{2}$
${ }^{1}$ Consultant pediatric cardiologist, AlJalila Hospital, UAE
${ }^{2}$ Internship, AlQassimi hospital, UAE
*Corresponding author: Mahmoud Alsoufi, Consultant
Pediatric Cardiologist, Al Qassimi Hospital-Sharjah, United
Arab Emirates, Tel: 00971-553405476; Email:
dr.m.soufi@ @otmail.com
Received: November 14, 2015 | Published: December 08,
2015

\section{Case Report}

53 years old male, presented to ER complaining of sever acute and sharp chest pain, he was a febrile, HR 125/min, BP 99/68, SPO2 $95 \%$ on RA.

a) ECG showed: Persistent ST elevation in anterior leads, and troponin-T was $>10 \mathrm{ng} / \mathrm{ml}$.

b) On examination: Pupils had sluggish reaction, chest had scattered wheezes bilaterally, and cardiovascular examination revealed pan systolic murmur all over pericardium. He was admitted with acute MI, complicated by cardiac arrest that required 20 minutes $C P R$.

Patient was thrombolysed properly, intubated and sedated and taken to cath lab for urgent PTCA. Echocardiography also showed severe LV systolic dysfunction, a kinetic mid and apical portions, large ventricular septal defect VSD sized $1.3 \mathrm{~cm}$ in the form of an oblique tunnel with significant left to right shunt (Figure 1).

Coronary angiogram also showed 3 coronary vessel disease occluded mid LAD by thrombus at bifurcation with large diagonal so recanalized and stented LAD and postdilated properly. LV gram showed large ventricular septal defect VSD 14 x10 mm in anterior septal wall with tunal shape associated with significant left to right shunt (Figure 2A \& 2B).

Patient deteriorated rapidly so intra-aortic balloon pump IABP and high doses of inotrops were started. We planned to closed this VSD by device in the catheterization laboratory on the same time but unfurtunalilly was did not have the suitable VSD dives size and No post MI device at all. Patient was shifted to cardiac intensive care unit for close observation and continue on inotrops, IABP and ventilation waiting for the suitable device.
He remined stable slightly and after 5 days we prepared for post MI device closure since we obtained post MI VSD devices. The procedure was done under general anesthesia since the patients sedated and Trans jugular venous approach and femoral artery we created Arterio-venous loop (Figure 2) and throw 12 F sheath a $20 \mathrm{~mm}$ post MI VSD device closure was deployed successfully in place according to VSD device closure techniq under the guidance of trans-esophageal echocardiography and fluoroscopy (Figure 3).

Patient was observed gain in cardiac intensive care unit and his vital signs started to be more stable so that IABP was removed and gradual weaning from high doses inotrops was achieved within 4 days. After 7 days patient was extubated and kept under observation due to pneumonia and CNS disturbances but after 10 days he improved dramatically and shifted to the ward before discharge home. Final echocardiography showed: VSD device in place with trivial residual shunt (Figure 4).

\section{Discussion}

Post MI VSD management still a big challenge and night mire for the cardiologist with very high mortality rate $(80 \%)$ within the first weeks $[1,9]$. Transcatheter post MI device closure is an excellent alternative method to close this defect and avoid surgical intervention which carry much higher risks and hope fully it will reduce this hight mortality rate.. $[7,8]$. Our case is the first case of post MI VSD which closed by device closure in UAE and this successful procedure was done after a good preparation and excellent team work and definitely it our experience will increase more and more especially with wide range of suitable devices ready now a days in the medical filed parallel with improved hands skills in this area [11]. 

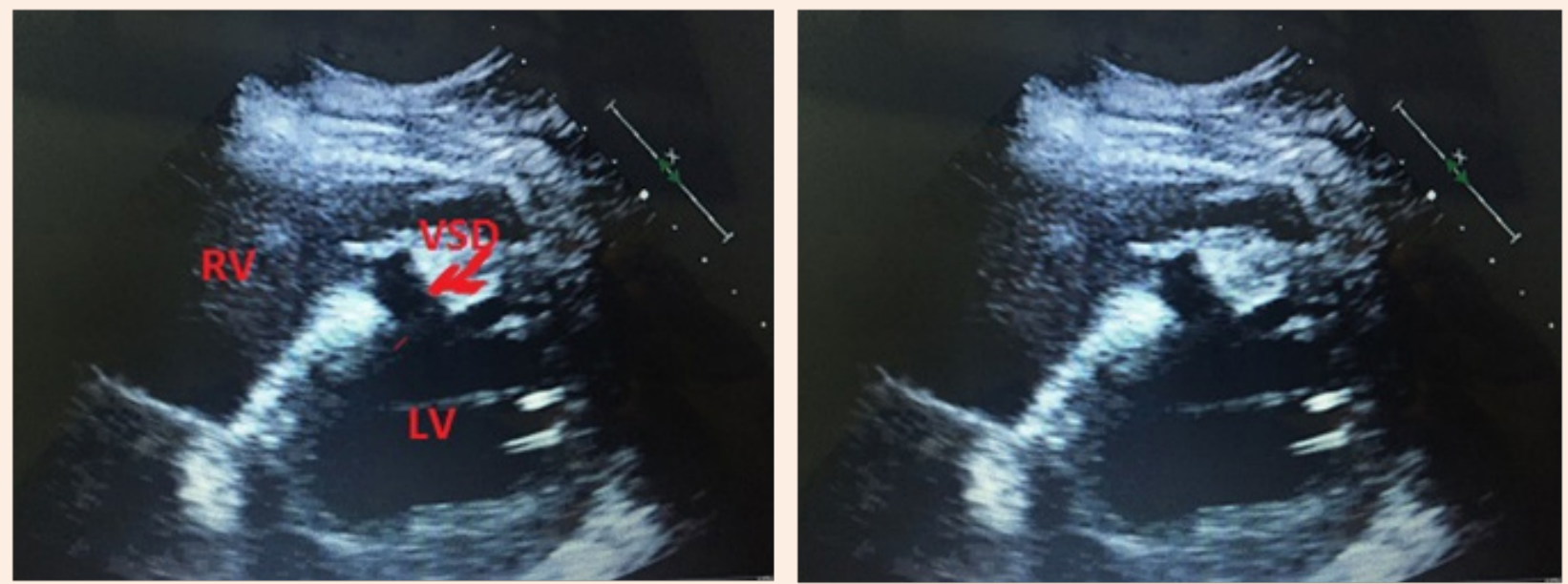

Figure 1: Post MI VSD by echocardiography.
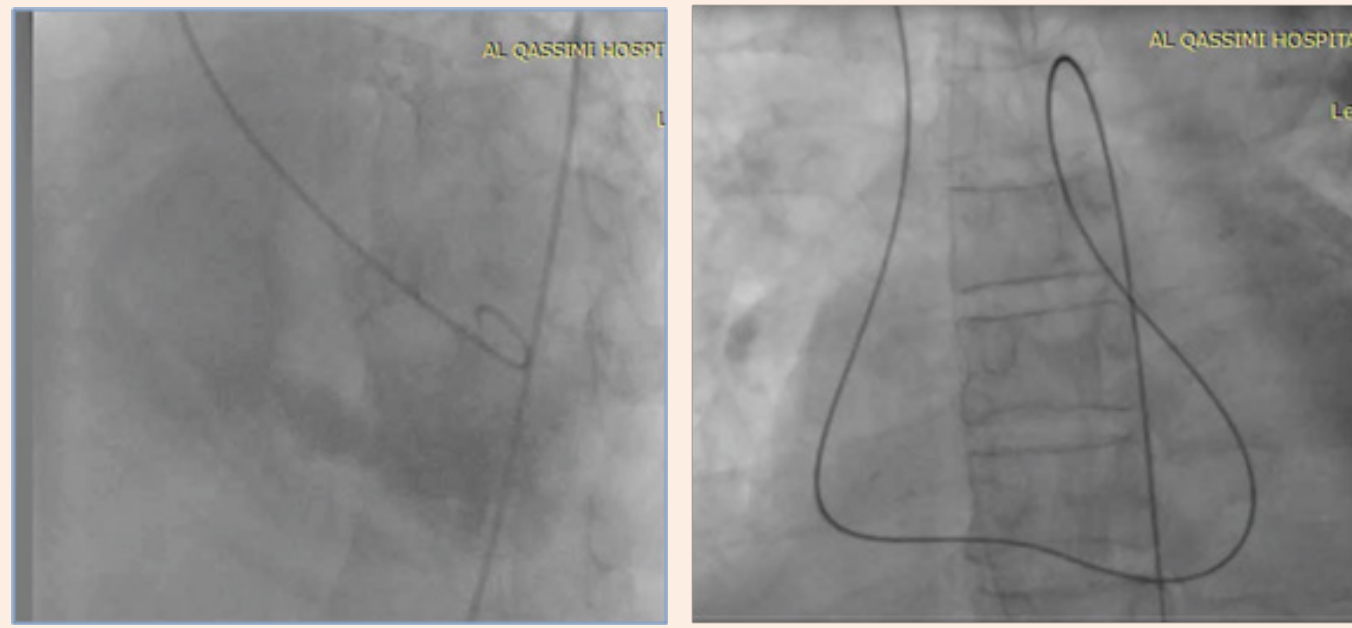

Figure 2A: LV angiogram showing large VSD.

Figure 2B: A-V loop throw VSD.
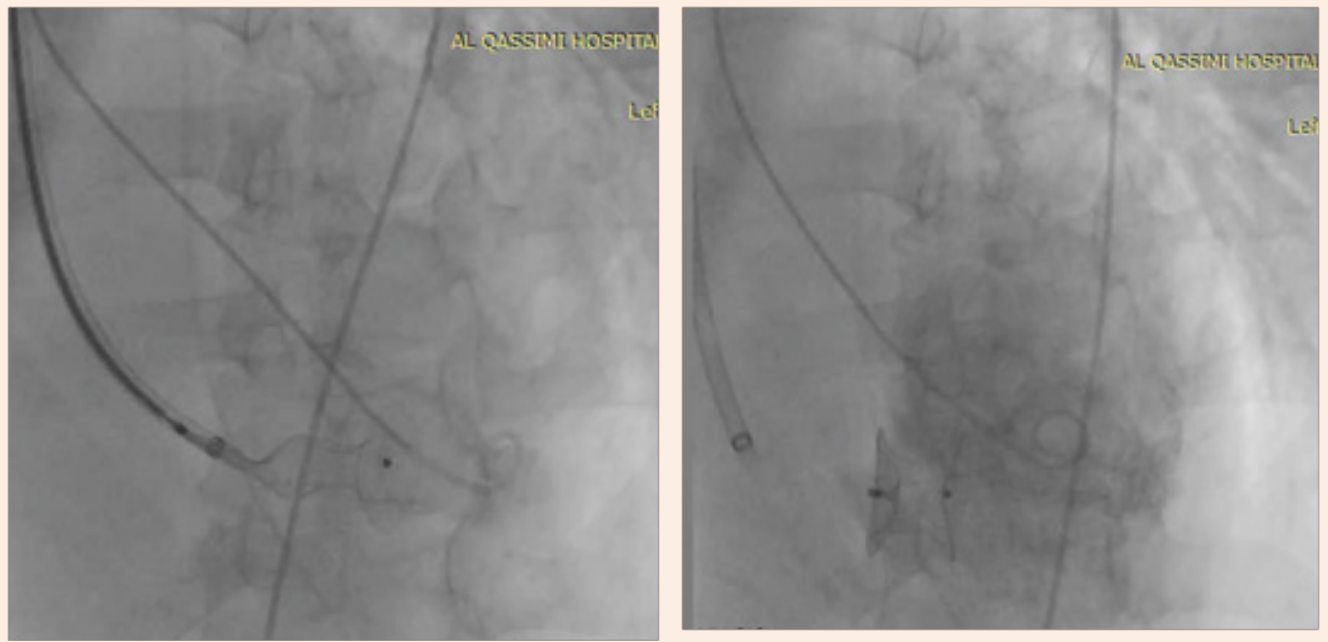

Figure 3: VSD device deployment and final angiogram. 

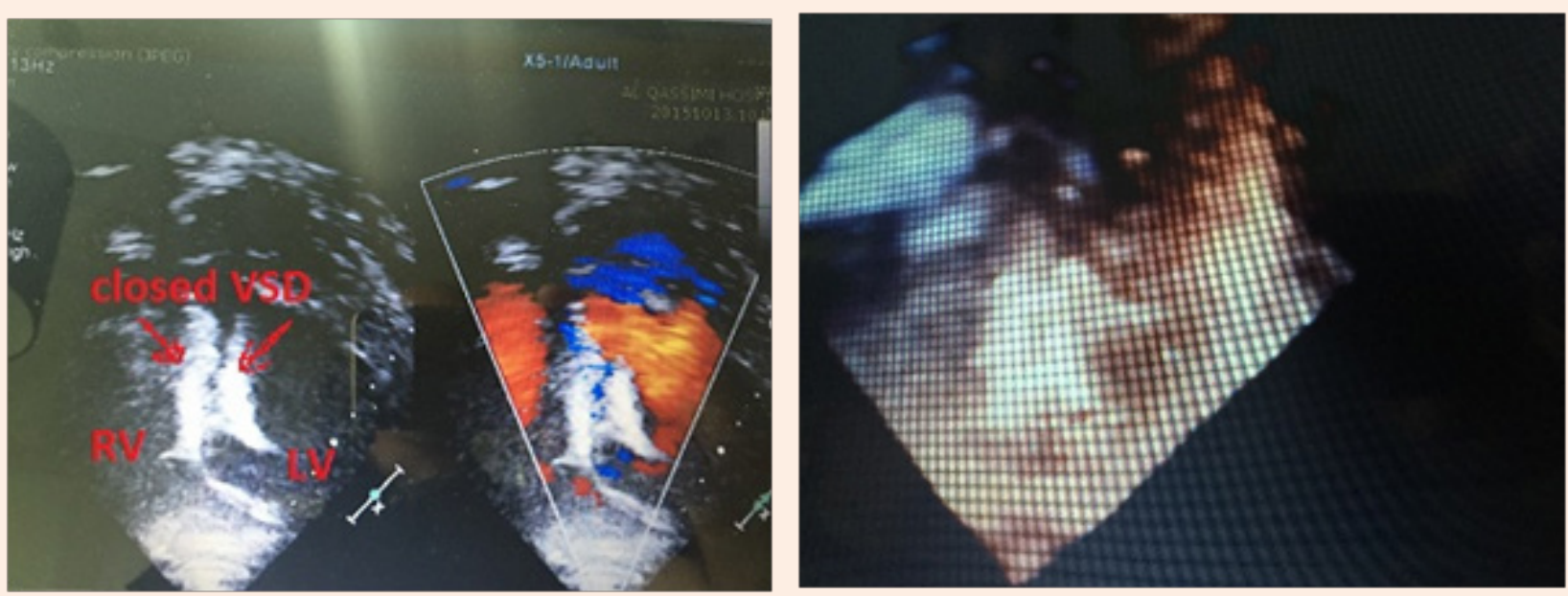

Figure 4: 2D and 3D echocardiograpgy show in VSD device in place with closed VSD.

\section{References}

1. Thiele H, Kaulfersch C, Daehnert I, Schoenauer M, Eitel I, et al (2009) Immediate primary transcatheter closure of postinfarction ventricular septal defects. Eur Heart J 30(1): 81-88.

2. Jacek B, Malgorzata S, Jacek K, Zbigniew K, Mariusz G (2007) Transcatheter closure of postinfarction ventricular defects using Amplatzer devices. Rev Esp Cardiol 60(5): 548-551.

3. Shabestari MM, Ghaderi F, Hamedanchi A (2013) Transcatheter closure of post-myocardial infarction ventricular septal rupture. Circ Cardiovasc Interv 6: 59-67.

4. Marinakis A, Vydt T, Dens J, Gewillig M, Van Deyk K, et al. (2007) Percutaneous transcatheter ventricular septal defect closure in adults with Amplatzer septal occluders. Acta Cardiol 62(4): 391-395.

5. Szkutnik M, Bialkowski J,Kusa J, Banaszak P, Baranowski J, et al. (2003) Postinfarction ventricular septal defect closure with Amplatzeroccluders. Eur J CardiothoracSurg 23: 323-327.

6. Martinez MW, Mookadam F, Sun Y, Hagler DJ (2007) Transcatheter closure of ischaemic and post-traumatic ventricular septal ruptures. Catheter CardiovascInterv 69(3): 403-407.
7. Ahmed J, Ruygrok PN, Wilson NJ, Webster MW, Greaves S, et al. (2008) Percutaneous closure of post-myocardial infarction ventricular septal defects: a single centre experience. Heart Lung Circ 17(2): 119-123.

8. Parsi A, Bruch L, Szurawitzki G, Boosfeldt C, Grad MO, et al. (2001) Transcatheter closure of muscular ventricular septal defects in two patients after myocardial infarction. J Interv Cardiol 14(2): 219-222.

9. Pohjola-Sintonen S, Muller JE, Stone PH, Willich SN, Antman EM, et al (1989) Ventricular septal and free wall rupture complicating acute myocardial infarction: experience in the Multicenter Investigation of Limitation of Infarct Size. Am Heart J 117(4): 809-818.

10. Moore CA, Nygaard TW, Kaiser DL, Cooper AA, Gibson RS (1986) Postinfarction ventricular septal rupture: the importance of location of infarction and right ventricular function in determining survival. Circulation 74: 45-55.

11. Crenshaw BS, Granger CB, Birnbaum Y, Pieper KS, Morris DC, et al (2000) Risk factors, angiographic patterns, and outcomes in patients with ventricular septal defect complicating acute myocardial infarction. GUSTO-I (Global Utilization of Streptokinase and TPA for Occluded Coronary Arteries) Trial Investigators. Circulation 101(1): 27-32. 